\title{
Forced arm use is superior to voluntary training for motor recovery and brain plasticity after cortical ischemia in rats
}

\author{
Armin Schneider ${ }^{1 * \dagger}$, Andreas Rogalewski ${ }^{2 \dagger}$, Oliver Wafzig ${ }^{1}$, Friederike Kirsch ${ }^{1}$, Norbert Gretz ${ }^{3}$, Carola Krüger ${ }^{1}$, \\ Kai Diederich², Claudia Pitzer ${ }^{1}$, Rico Laage ${ }^{1}$, Christian Plaas$^{1}$, Gerhard Vogt $^{1}$, Jens Minnerup ${ }^{2 \dagger}$ and \\ Wolf-Rüdiger Schäbitz $z^{2 *}$
}

\begin{abstract}
Background and purpose: Both the immobilization of the unaffected arm combined with physical therapy (forced arm use, FAU) and voluntary exercise (VE) as model for enriched environment are promising approaches to enhance recovery after stroke. The genomic mechanisms involved in long-term plasticity changes after different means of rehabilitative training post-stroke are largely unexplored. The present investigation explored the effects of these physical therapies on behavioral recovery and molecular markers of regeneration after experimental ischemia.

Methods: 42 Wistar rats were randomly treated with either forced arm use (FAU, 1-sleeve plaster cast onto unaffected limb at 8/10 days), voluntary exercise (VE, connection of a freely accessible running wheel to cage), or controls with no access to a running wheel for 10 days starting at 48 hours after photothrombotic stroke of the sensorimotor cortex. Functional outcome was measured using sensorimotor test before ischemia, after ischemia, after the training period of 10 days, at 3 and 4 weeks after ischemia. Global gene expression changes were assessed from the ipsi- and contralateral cortex and the hippocampus.

Results: FAU-treated animals demonstrated significantly improved functional recovery compared to the VE-treated group. Both were superior to cage control. A large number of genes are altered by both training paradigms in the ipsi- and contralateral cortex and the hippocampus. Overall, the extent of changes observed correlated well with the functional recovery obtained. One category of genes overrepresented in the gene set is linked to neuronal plasticity processes, containing marker genes such as the NMDA 2a receptor, PKC Z, NTRK2, or MAP $1 \mathrm{~b}$.

Conclusions: We show that physical training after photothrombotic stroke significantly and permanently improves functional recovery after stroke, and that forced arm training is clearly superior to voluntary running training. The behavioral outcomes seen correlate with patterns and extent of gene expression changes in all brain areas examined. We propose that physical training induces a fundamental change in plasticity-relevant gene expression in several brain regions that enables recovery processes. These results contribute to the debate on optimal rehabilitation strategies, and provide a valuable source of molecular entry points for future pharmacological enhancement of recovery.
\end{abstract}

\footnotetext{
* Correspondence: schneider@sygnis.de; wolf.schaebitz@evkb.de

${ }^{\dagger}$ Equal contributors

'SYGNIS Bioscience, Heidelberg, Germany

${ }^{2}$ Neurology Department Bethel EVKB Bielefeld and Dept. of Neurology,

University of Muenster, Muenster, Germany

Full list of author information is available at the end of the article
} 


\section{Introduction}

Stroke is the leading reason for permanent disability in the western world [1] and therefore one of the biggest and growing burdens for welfare systems. Improving care and treatment of stroke includes both development of new pharmacological strategies in the acute phase, as well as improvements in approaches that stimulate functional recovery after stroke by enhancing brain-inherent plasticity mechanisms. Up to now, despite several attempts at developing pharmacological means for enhancing recovery [2], the only measures to support motor recovery of stroke patients is physical therapy. Numerous questions arise around problems of optimal timing, frequency, and type of therapy used. Immobilization of the unaffected arm combined with physical therapy, the so called forced use paradigm, was shown to improve motor function of the impaired arm weeks after unilateral stroke in humans [3-6]. Not completely understood are timing and intensity of the training. This is important because experimental and clinical data indicate that an early overuse of the impaired limb could worsen functional outcome and exaggerate lesion size [7-10]. On the other hand, voluntary treatment paradigms where timing and intensity are controlled by the affected individual can also improve recovery and induce plasticity processes after focal cerebral ischemia.

Although it is clear that physical therapy enhances endogenous plasticity mechanisms of the brain the genomic mechanisms involved in plasticity changes after different means of rehabilitative training post-stroke are largely unexplored. Areas of the post-stroke brain that are of particular interest in view of plastic changes include the infarct-adjacent cortex (e.g. [11]), the contralateral homotopic cortex (e.g. [12]), and the hippocampus (e.g. [13]).

We have therefore set out to compare forced vs. voluntary measures of "rehabilitation" training in rodents regarding their outcome, and associated changes in gene expression, as clarification of these changes could allow a better understanding of the underlining mechanisms as well as a pharmacological targeting of mechanisms involved in rehabilitation-induced plasticity.

\section{Methods}

\section{Ischemia model}

All animal experiments were conducted in accordance with an institutionally approved protocol following the governmental authorities Landesamt für Natur, Umwelt und Verbraucherschutz Nordrhein- Westfalen. Male Wistar rats (Charles River; 280 to 320 g) were anesthetized with an i.p. injection of xylazine hydrochloride (Bayer, Leverkusen Germany) and ketamine hydrochloride (WDT, Garbsen, Germany). A PE-50 polyethylene tube was inserted into the right femoral artery for continuous monitoring of mean arterial blood pressure and blood gases. The right femoral vein was cannulated by a PE-50 tube for treatment infusion. During the experiment rectal temperature was monitored and maintained at $37^{\circ} \mathrm{C}$ by a thermostatically controlled heating pad (Föhr Medical Intruments, Germany).

Photothrombotic ischemia was induced in the rat parietal cortex $[14,15]$. Animals were placed in a stereotaxic frame, and the scalp was incised for exposure of the skull surface. For illumination, a laser was placed stereotaxically onto the skull $0.5 \mathrm{~mm}$ ventral to the bregma and $4 \mathrm{~mm}$ lateral from the midline. The skull was illuminated with a laser spot of $8 \mathrm{~mm}$ in diameter (G Laser Technologies) for 20 minutes. During the first 2 minutes of illumination, the dye rose bengal $(0.133 \mathrm{~mL} / \mathrm{kg}$ body weight, $10 \mathrm{mg} / \mathrm{mL}$ saline) was injected intravenously. Sham-operated animals underwent the same experimental procedures as described above without infusion of rose bengal and illumination. After surgery, the catheters were removed, and the animals were allowed to recover from the anesthesia and given food and water ad libitum. All animal experiments followed ethical standards, and protocols were approved by the respective government authorities.

\section{Exercise treatment}

Forced Arm Use (FAU)-treated animals were fitted with a 1-sleeve plaster cast. The upper torso was wrapped in soft felt, and the ipsilateral forelimb was wrapped in felt and positioned in a naturally retracted position against the animal's sternum. After a period of 4 days, the procedure was suspended for 48 hours. At day 6 of the treating period, the cast was reapplied. Animals in the voluntary exercise group (VE) were housed individually in a cage with a running wheel assembly for 10 days. Each revolution of the freely accessible wheel was electronically counted and recorded in this time period. Animals in the cage control group were housed individually in standard laboratory cages. These animals received no specific training.

\section{Behavioral testing}

All animals were operated and tested in parallel (1 animal per group at once). In all animals, behavioral tests were performed at baseline before ischemia, after ischemia (24 h after operation procedure), after the training period of 10 days (day 13), and at 3 and 4 weeks after ischemia by an investigator blinded to the experimental groups. The behavioral tests after ischemia and after the training period of 10 days were performed with sufficient distance to anesthesia procedure. The experimental setup scheme is given in Figure 1.

\section{Adhesive removal test}

The adhesive removal test was done at baseline before ischemia, after ischemia, after the training period of 10 


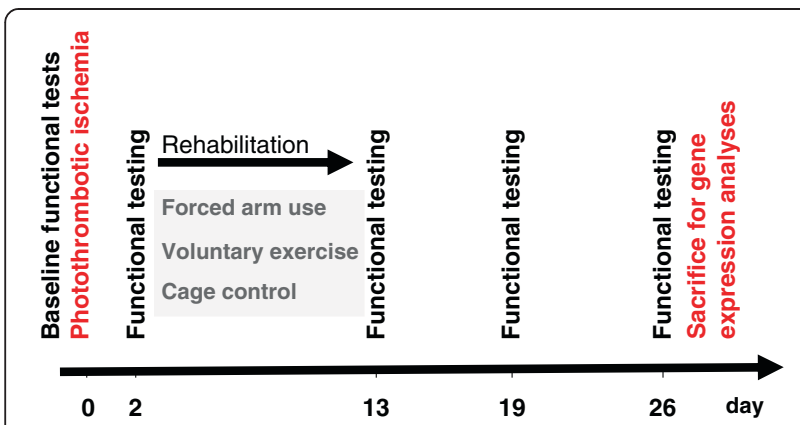

Figure 1 Experimental design. 42 Wistar rats were randomly treated with either FAU (group 1; 1-sleeve plaster cast onto unaffected limb at 8/10 days), VE (group 2; connection of a freely accessible running wheel to cage), or a cage control condition (group 3) for 10 days starting at 48 hours after photothrombotic stroke of sensorimotor cortex (day 3 to 13). Functional outcome was measured using two sensorimotor tests focused on motor control of the front paw (adhesive tape removal and cylinder tests) at baseline before ischemia (day 0), 2 days after ischemia (day 2), after the training period of 10 days (day 13), and at 3 (day 19) and 4 weeks (day 26) after ischemia by an investigator blinded to the experimental groups. Animals were sacrificed at 4 weeks after induction of stroke. For gene expression changes samples were taken from the ipsi- and contralateral cortex and the hippocampus, and hybridized to Affymetrix DNA arrays.

days, and at 3 and 4 weeks after ischemia to test sensory and motor function. Initially, 2 pieces of adhesivebacked paper dots $\left(113.1 \mathrm{~mm}^{2}\right)$ were used as bilateral tactile stimuli on the dorsal paw of each forelimb. The time to remove each stimulus from the forelimbs was recorded 3 trials per day for each forepaw. Individual trials were separated by 5 minutes. Before surgery, animals were trained for 3 days.

\section{Cylinder test}

The cylinder test was done at baseline before ischemia, after ischemia, after the training period of 10 days, and at 3 and 4 weeks after ischemia to test motor and coordinative function. The animals were not trained before ischemia. The rats were placed in a transparent Plexiglas cylinder (20 cm high, $20 \mathrm{~cm}$ diameter) placed on a glass table for 5 minutes and recorded on video. For analysis, the number of independent placements of the forelimbs was measured over a time period of 30 seconds. The analysis was performed off-line based on the video recording.

\section{Gene expression analysis}

22 brains were analyzed by gene expression analysis (Cage 01-08, VE 01-07, FAU 01-07). Horizontal cryosections $(8 \mu \mathrm{m})$ were prepared from brains of HBSS (hanks balanced salt solution)-perfused animals. Sections were thionin-stained, and laser dissection was performed with a Laser-Dissection Microscope (Leica Microsystems LMD6000, CryLaS FTSS 355-50 laser, Hitachi HV-D20 camera). Additional file 1: Figure S1 shows the relative position of the horizontal sections used for dissection, and an exemplary view on the stained hippocampus before and after laser microdissection. Per Section 3 areas were dissected: the ipsi- and contralateral cortex, and the ipsilateral hippocampus. The cortex areas for dissection were located immediately posterior to the lesion site with a diameter of $2 \mathrm{~mm}$, and the corresponding area on the contralateral cortex. Per animal dissection material from 3 consecutive sections was pooled.

RNA was isolated using the Rneasy micro Kit (Qiagen, Hilden, Germany). RNA was amplified over 2 rounds using a proprietary protocol [16,17]. In brief, RNA was precipitated, resuspended, and mixed with T7-tagged dT21V oligonucleotides. 2 rounds of amplification were performed using T7-RNA polymerase. The conditions used guarantee linear amplification with low RNA input material. Biotin-marked second-round aRNA was produced with an NTP-mix composed of: Biotin-11-CTP and Biotin-16-UTP (PerkinElmer) (2 $\mathrm{mM}$ f.c.) and the T7-Megascript kit (Applied Biosystems/Life Technologies GmbH, Darmstadt Germany). Biotin-labelled amplified RNA (aRNA) was controlled for size distribution and amount using the Agilent 2100 Bioanalyzer with the RNA 6000 Nano LabChip kit (Agilent Technologies Deutschland $\mathrm{GmbH}$, Böblingen, Germany) (Additional file 2: Figure S2). Hybridization was done with Affymetrix GeneChip ${ }^{\circ}$ Rat Genome 2302.0 Arrays. Arrays were analyzed by an Affymetrix GeneArray Scanner3000 (University of Mannheim, Center for medical research (ZMF)).

After array hybridization data were analyzed by Genesifter software (www.genesifter.net). Initial quality analysis revealed high homogeneity of hybridization signal distributions (Additional file 3: Figure S3). Data were normalized over all arrays using GC-RMA. Statistical testing was done using two-way ANOVA for the factors location and treatment. False discovery rate was controlled using the BenjaminiHochberg procedure.

\section{Statistics}

Experiments were performed in a completely randomized and blinded manner. Statistical analyses were done using JMP 8.01 (SAS, Cary, NC, USA). Gene expression analysis statistics were done using T-test and Benjamini-Hochberg FDR (false discovery rate). Sensorimotor measurements were analyzed with 2-way repeated-measures analysis of variance followed by the Fisher protected least significance difference test. An $\alpha$ error rate of 0.05 was taken as the criterion for significance. 


\section{Results}

Forced training is superior to voluntary training for motor recovery

Photothrombotic ischemia resulted in all animals in a welldefined infarct in the right parietal cortex (see Figure 2). All animals displayed paresis of the left forearm. 48 rats were included in the operation procedure, five animals died. The remaining 43 animals were randomly treated with either forced arm use (FAU, induced by a cast to the unaffected arm), voluntary exercise (VE, animals allowed free access to a running wheel), or a cage control condition. In this study,

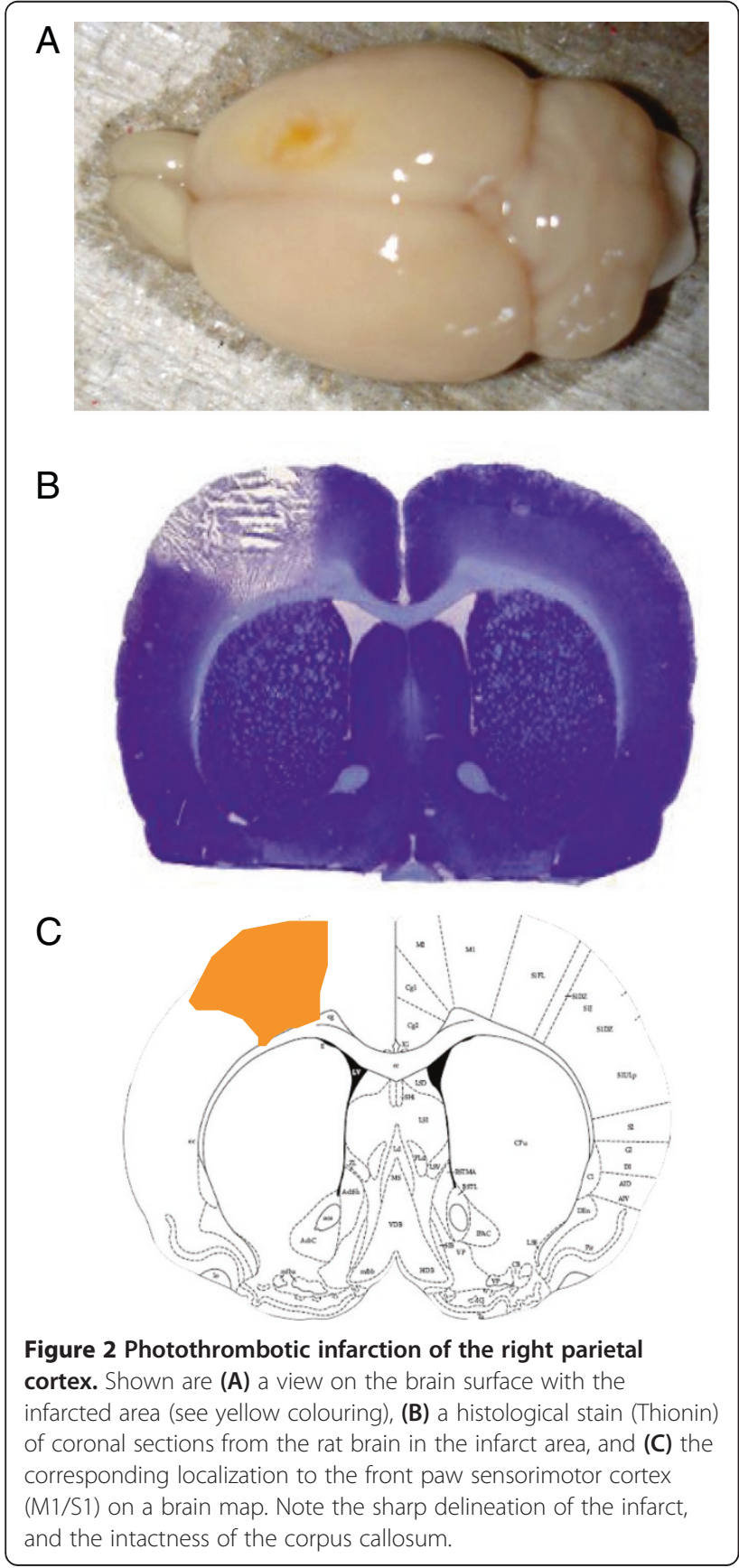

infarct volumes were not determined. In previous studies we were able to show that this type of physical training had no effect on this type of small cortical infarctions $[18,19]$.

Recovery of animals was measured up to 4 weeks following ischemia using two tests centered on motor performance in the front paws, the adhesive tape removal test, and the cylinder test. The experimental setup is shown in Figure 1.

Rehabilitative training after focal cerebral ischemia with both forced arm use (FAU) and voluntary exercise (VE) compared to cage control condition significantly improved functional recovery after focal ischemia (Figure 3). This improvement in functional neurological outcome was visible directly after the training period and remained stable over 4 weeks after ischemia. Neurological recovery was clearly better after forced training compared to voluntary running (Figure 3).

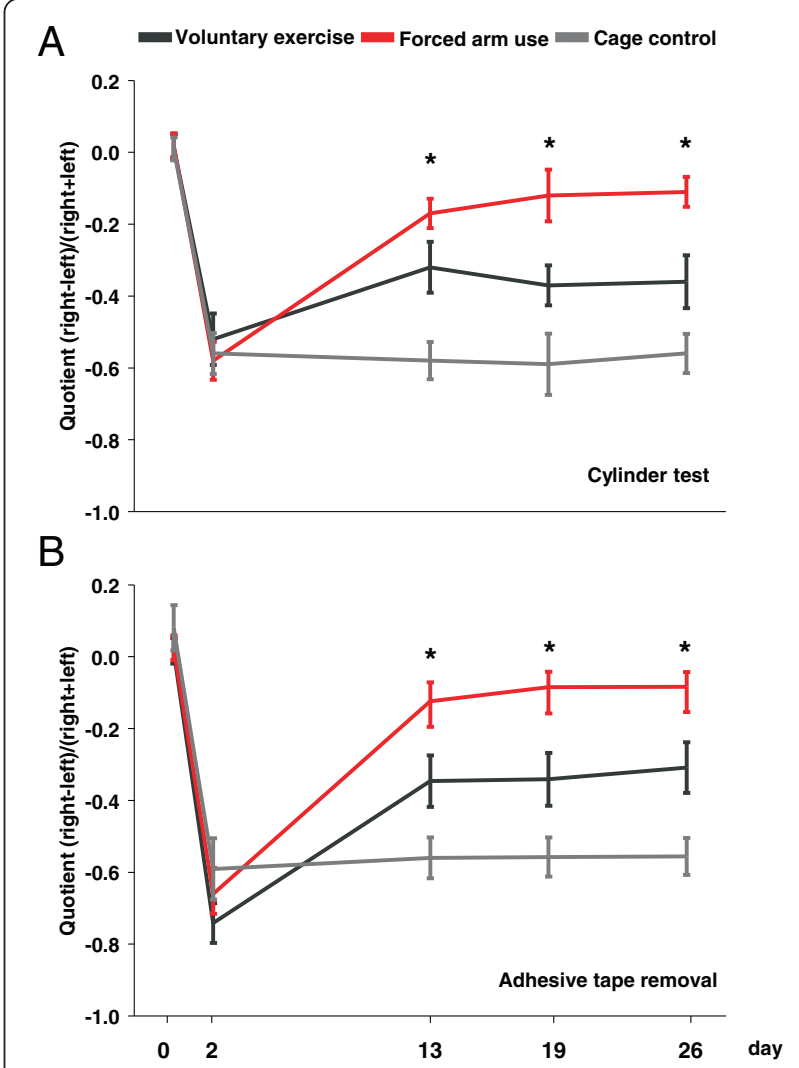

Figure 3 Functional motor recovery of rats subjected to different training paradigms. Functional improvement of the left, paretic forepaw after photothrombotic stroke measured with the cylinder test (A) and the Adhesive tape removal task (B). Note the clear improvement of both forced (red curve) and voluntary (black curve) training compared to untreated animals (grey curve). $\left({ }^{*} \mathrm{p}<0.05\right.$, ANOVA, Fisher's test). 


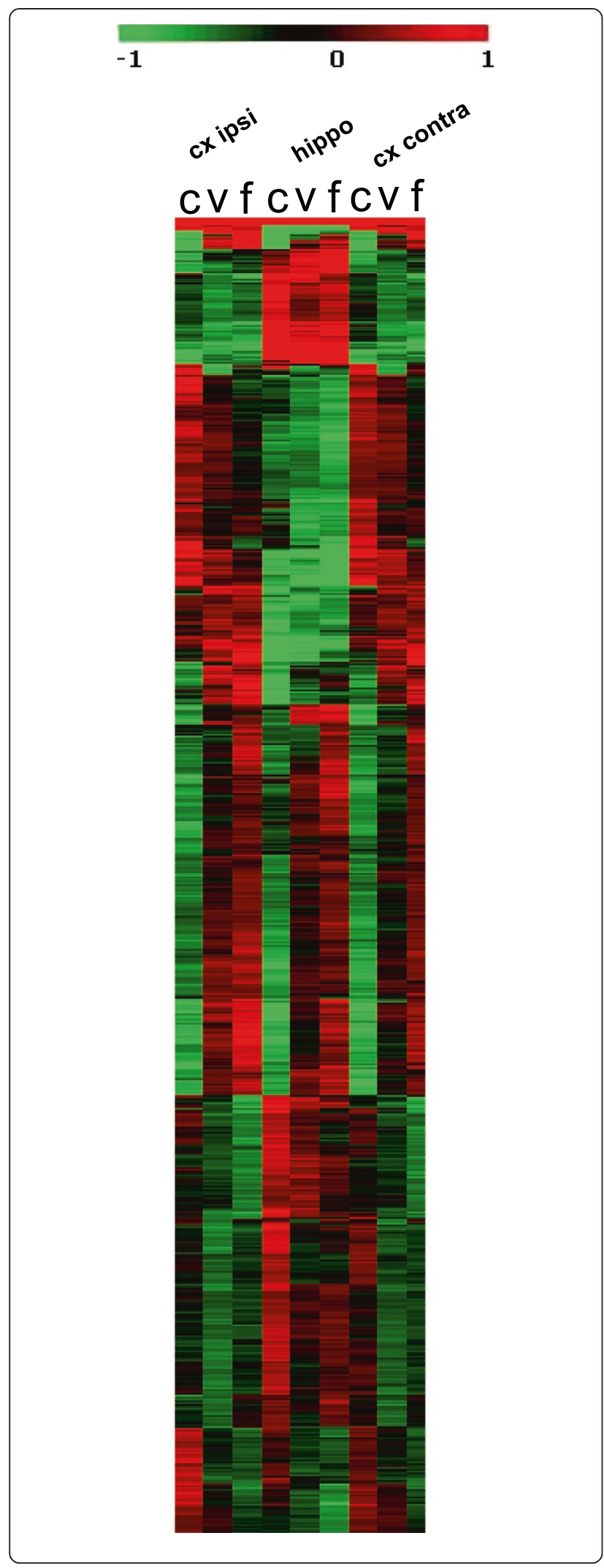

Figure 4 Heat map showing an excerpt from the primary analysis of gene expression data. Red, up regulated genes, green, down regulated genes. The regulation factors are centered over each row. Genes are clustered according to similar behavior across the experimental groups. The three exercise paradigms show clearly different patterns.

\section{Gene expression changes reflect the different effects of training}

We analyzed three regions of bona fide interest to motor recovery processes linked to exercise: a $2 \mathrm{~mm}$ broad cortical area caudally adjacent to the infarct border, the corresponding area of the contralateral cortex, and the whole ipsilateral hippocampus. A total of 22 brains were analyzed, 8 from the control group, 7 from both exercise groups. Animals were randomly selected for the analysis. Gene expression was performed by laser-mediated dissection of the tissue, amplification of mRNA, and hybridization to DNA arrays.

For an initial view on the data we contrasted all training groups and all locations to each other using scatter plots (Additional file 4: Figure S4). This already suggested a strong influence on gene expression of the two training praradigms in all locations examined. We then performed a 2-way ANOVA analysis with the two factors location and exercise condition. A total of 3613 probe sets were significantly influenced by the factor exercise (significance criteria: $\mathrm{p}<0.01$ after multiple testing adjustment for Benjamini-Hochberg false discovery rate) (Additional file 5: Table S1). Figure 4 shows an excerpt heat map from the initial hierarchical clustering.

To obtain more information on the patterns of regulation observed we clustered the gene set using the PAM algorithm (patterning around medoids) [20]. This revealed that there was an astonishingly high degree of similar behavior patterns of individual genes across the three brain areas sampled (Figure 5; clusters $=8$, average silhouette width $=0.383$, distance measure used $=$ correlation). Indeed, there is no cluster formed where genes in the three treatment paradigms behaves fundamentally different dependent on the location the sample was taken from (i.e. in cluster 1 genes have the highest expression in the cage control animals, go down with voluntary training, and up again with forced training whereas in cluster 2 genes increase continuously in expression from control over voluntary to forced training, but have the same behavior in cortex or hippocampus). We believe that this is quite a remarkable finding to see that training influences all examined regions in the same way. Also, while many clusters indeed follow one direction (up or down) from cage controls in the direction control - voluntary - forced training paralleling the differences in behavioral recovery, a few clusters show 

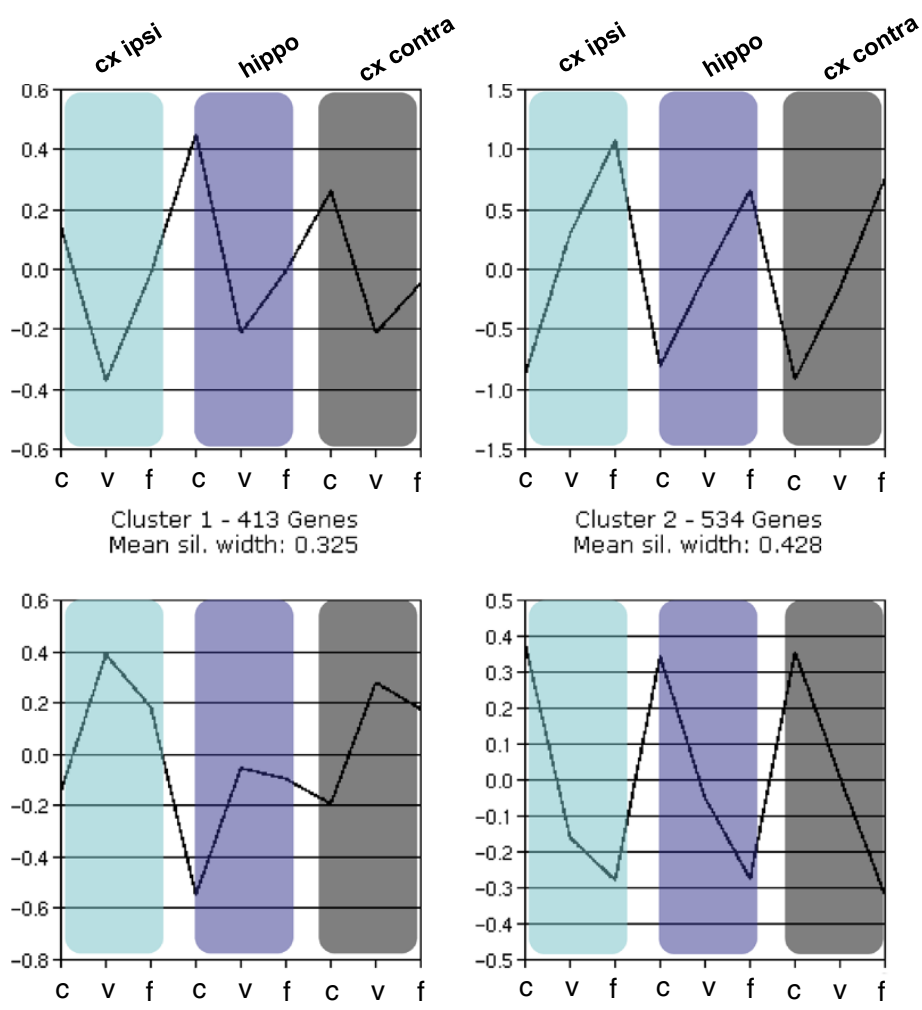

Cluster 3 - 557 Genes

Mean sil. width: 0.392

Cluster 4 - 522 Genes

Mean sil. width: 0.421

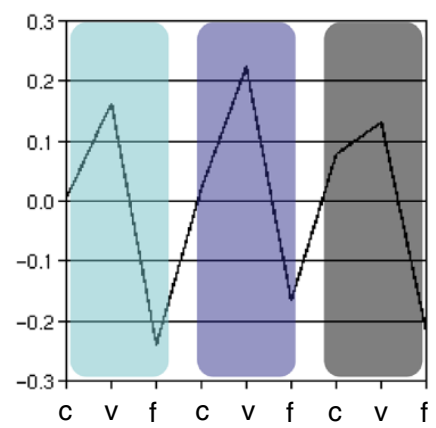

Cluster 5 - 269 Genes

Mean sil. width: 0.232

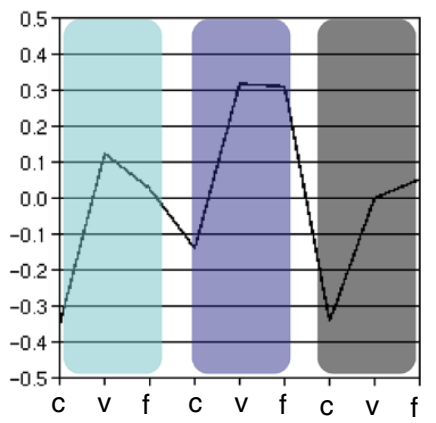

Cluster 6 - 467 Genes

Mean sil. width: 0.310

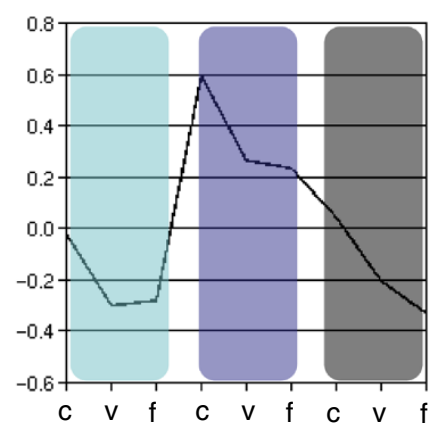

Cluster 7 - 355 Genes

Mean sil. width: 0.425

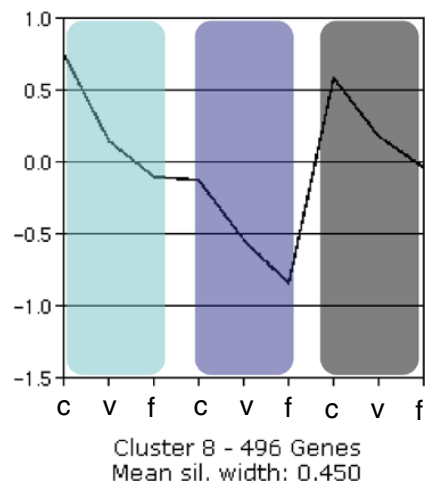

Figure $\mathbf{5}$ (See legend on next page.) 
(See figure on previous page.)

Figure 5 PAM clustering of regulation patterns observed over the training paradigms and regions studied. The gene set of 3616 differently regulated genes was subjected to the PAM algorithm clustering (patterning around medoids) (clusters $=8$, average silhouette width $=0.383$, distance measure used $=$ correlation). $C$, control; $v$, voluntary and f, forced training. While most clusters follow one direction (up or down) from cage controls in the direction control - voluntary - forced training which correlates to the degree of recovery observed in the behavioral tests, a few clusters show divergent behavior for groups of genes in voluntary and forced training (cluster 3, 5, and partially 4).

divergent behavior for groups of genes in voluntary and forced training (cluster 3, 5, and partially 4).

The notion of a strong congruence of gene regulation in the three different regions examined was also underscored by a principal component analysis (PCA). Proximity of the main group vectors was determined much more by treatment than by origin of the samples analyzed (Figure 6).

To obtain information on the functional significance of the genes regulated we performed relative enrichment analyses using DAVID (http://david.abcc.ncifcrf.gov/) $[21,22]$. We used the functional annotation clustering tool that groups significantly overrepresented genes from different categorization systems (gene ontology, KEGG, SP-PIR etc.) in the dataset into summary categories. The following categories were identified as significant and had a relative enrichment of at least 2-fold: mitochondrion, RNA splicing/processing, cytoskeleton, ATP binding, Huntington's/Alzheimer's/Parkinson's disease, zinc binding, microtubule, protein complex assembly, transcription regulation, cytoplasmic/synaptic vesicles, protein synthesis initiation, protein degradation, synapse/postsynaptic density, neuron projection, regulation of neuronal synaptic plasticity, synaptic transmission, membrane organization. The dominating themes hit by a number of clusters appear to be mitochondrion, protein degradation, transcription, and neuronal plasticity.

We next concentrated on genes linked to neuronal plasticity for further analysis. We manually screened the list of genes that were at least 1.3-fold up regulated in the mean (over all three regions examined) for genes that have been experimentally shown to have significance for plasticity. The resulting list of genes together with their regulation factors is given in Table 1 . This list is made up of hallmark genes for neuronal plasticity, such as the NMDA 2A receptor (NMDAR2A/GRIN2A) [23-27] (mean up regulation 2.5-fold), NTRK2/TrkB (BDNF receptor) [28-32] (mean up regulation 1.69-fold),

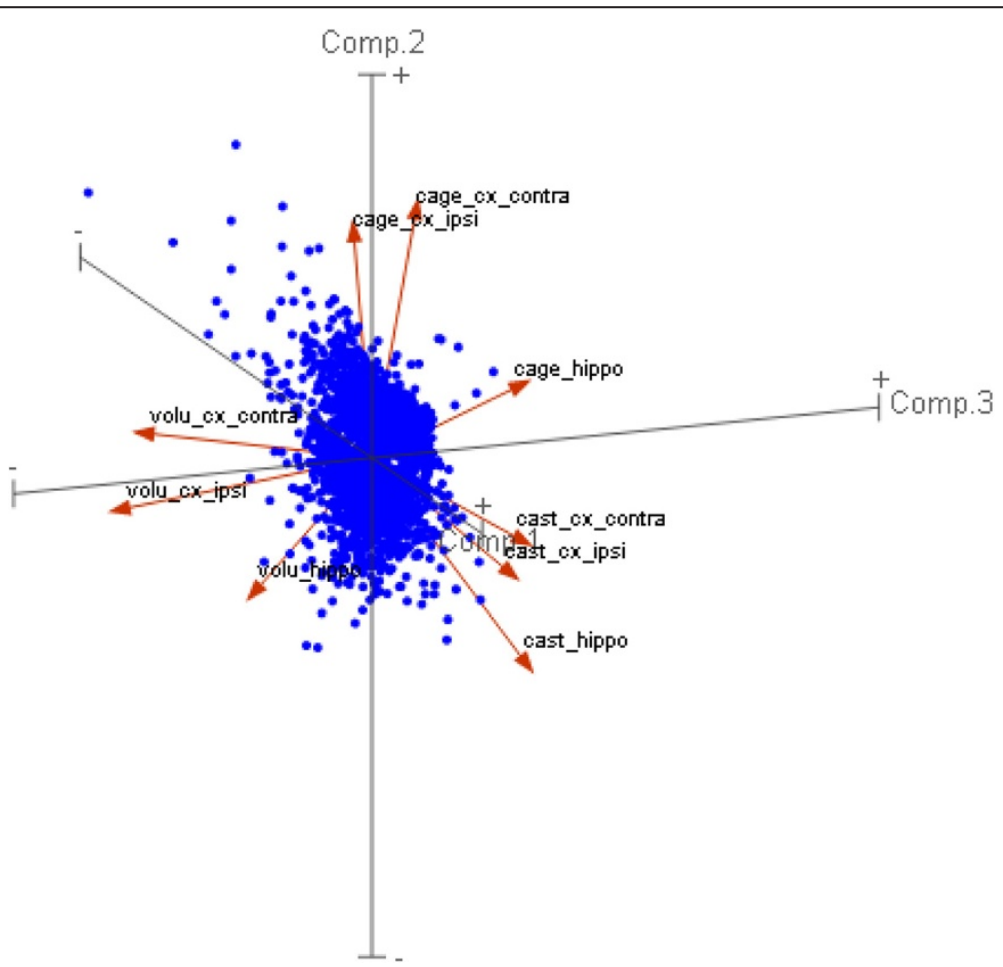

Figure 6 Principal component analysis (PCA) of all genes significantly regulated. All 3616 regulated genes were subjected to principal component analysis (PCA). Closest together are group vectors that are related by treatment, independent of location. Note that still the two cortex samples are closer together than the hippocampus vector in each treatment group. 
Table 1 Selection of up regulated genes linked to neuronal plasticity

\begin{tabular}{|c|c|c|c|c|c|c|}
\hline \multirow[b]{2}{*}{ Gene title } & \multicolumn{2}{|l|}{ Ipsi cx } & \multicolumn{2}{|l|}{ Hippocampus } & \multicolumn{2}{|l|}{ Contra cx } \\
\hline & Factor volu/control & Factor cast/control & Factor volu/control & Factor cast/control & Factor volu/control & Factor cast/control \\
\hline \multicolumn{7}{|l|}{ Receptors/postsynaptic plasticity } \\
\hline Glutamate receptor, ionotropic, N-methyl D-aspartate 2A & 2.16 & 2.63 & 2.66 & 2.69 & 2.41 & 2.31 \\
\hline Glutamate receptor, ionotropic, kainate 1 & 1.35 & 1.47 & 1.79 & 2.08 & 1.20 & 1.81 \\
\hline Glutamate receptor interacting protein 1 & 1.11 & 1.45 & 0.95 & 1.53 & 1.13 & 1.67 \\
\hline Neurotrophic tyrosine kinase, receptor, type 2 & 1.58 & 1.60 & 1.60 & 1.60 & 1.52 & 2.20 \\
\hline Homer homolog 1 (Drosophila) & 1.39 & 2.07 & 1.36 & 1.87 & 1.33 & 2.16 \\
\hline Protein kinase $C$, zeta & 1.92 & 1.54 & 1.52 & 1.12 & 1.32 & 1.11 \\
\hline \multicolumn{7}{|l|}{ Neuronal morphological plasticity } \\
\hline Dynein, axonemal, light chain 1 & 2.40 & 2.96 & 1.91 & 2.52 & 1.78 & 2.39 \\
\hline Neurexin 1 & 2.09 & 1.88 & 2.30 & 2.44 & 2.30 & 2.50 \\
\hline Microtubule-associated protein 1B & 2.01 & 2.29 & 2.12 & 2.17 & 2.54 & 2.17 \\
\hline Microtubule-associated protein tau & 1.82 & 1.84 & 1.79 & 1.79 & 1.87 & 1.89 \\
\hline Tenascin R & 1.33 & 2.04 & 1.62 & 2.52 & 1.98 & \\
\hline MAP/microtubule affinity-regulating kinase 3 & 1.76 & 1.61 & 1.32 & 1.23 & 1.44 & 2.45 \\
\hline Dynein cytoplasmic 1 light intermediate chain 1 & 1.27 & 1.14 & 1.78 & 1.53 & 1.34 & 1.29 \\
\hline \multicolumn{7}{|l|}{ Connectivity, pathfinding, plasticty } \\
\hline Slit homolog 2 (Drosophila) & 1.95 & 2.13 & 1.75 & 1.87 & 2.02 & 2.05 \\
\hline Eph receptor B2 & 1.39 & 1.40 & 1.26 & 1.58 & 1.39 & 1.44 \\
\hline Eph receptor B3 & 0.96 & 1.33 & 1.48 & 2.10 & 1.09 & 1.62 \\
\hline EphA5 & 1.83 & 2.50 & 1.77 & 2.22 & 1.74 & 2.35 \\
\hline \multicolumn{7}{|l|}{ Ion channel } \\
\hline Sodium channel, voltage-gated, type III, beta & 1.70 & 1.62 & 2.19 & 2.05 & 1.84 & 2.60 \\
\hline \multicolumn{7}{|l|}{ Presynapse } \\
\hline Synaptotagmin V & 1.22 & 1.89 & 1.12 & 1.25 & 1.28 & 1.83 \\
\hline Syntaxin 8 & 1.47 & 1.20 & 1.60 & 1.33 & 1.38 & 1.33 \\
\hline
\end{tabular}



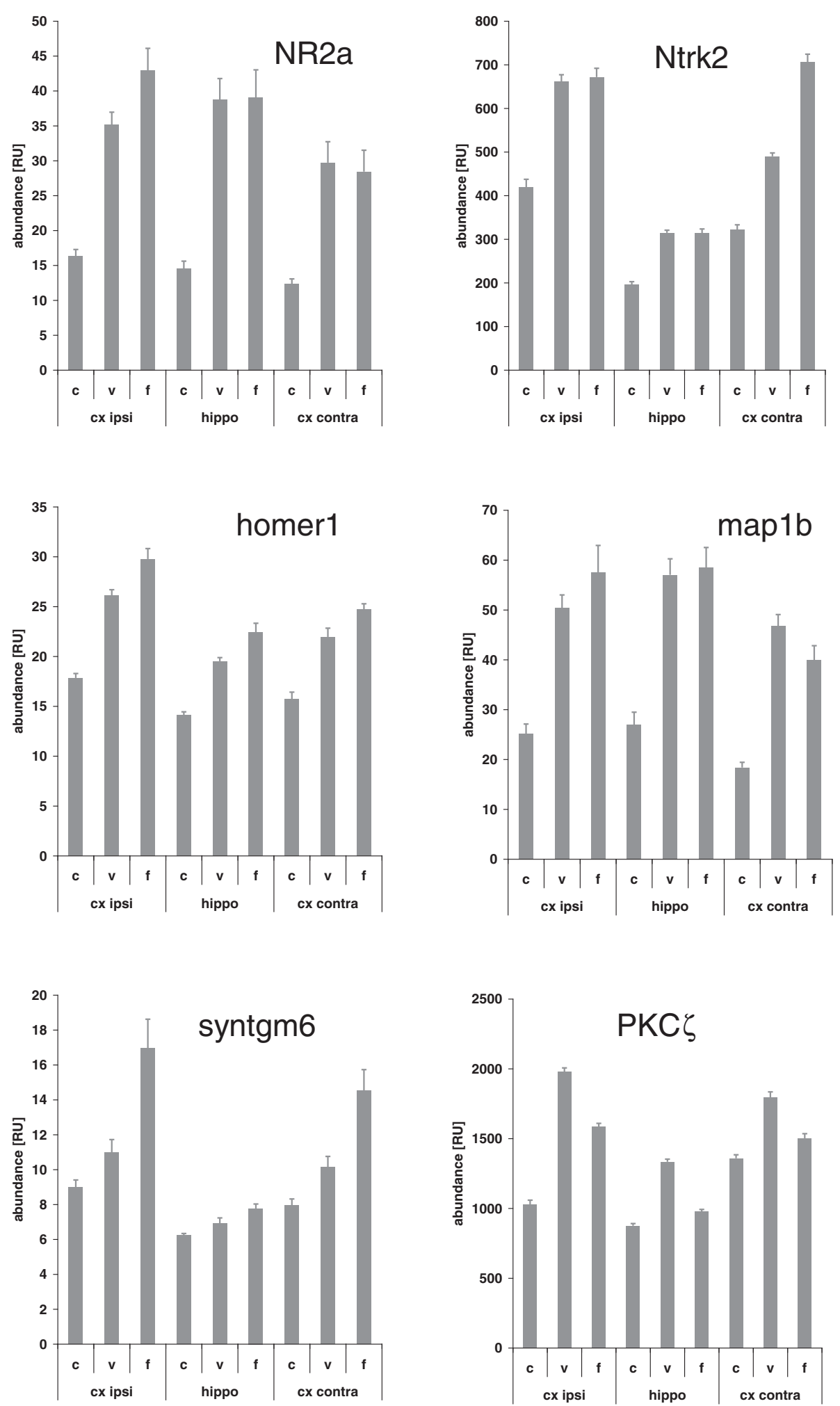

Figure 7 Selection of regulation details of 6 genes linked to neuronal plasticity. The detailed regulation data for a selection of 6 genes that have the strongest evidence-based link to learning processes and plasticity is depicted (mean +/- SEM). C, control; v, voluntary and f, forced training. Cx ipsi: cortex ipsilateral; hippo, hippocampus; cx contra, cortex contralateral. 
the GRIK1/GLUR5 glutamate receptor [33-38] (mean up regulation 1.65), Grip1 [39-42] (mean up regulation 1.38-fold), homer1 [43-47] (mean up regulation 1.55-fold), or the atypical protein kinase $C \zeta$ [48-52] (mean up regulation 1.36-fold). Interestingly, we also found the mRNA for KIBRA/WWC1 up regulated (mean up regulation 1.5 -fold), a protein strongly linked to human learning and memory [53-60]. The detailed regulation data for a selection of 6 genes that have the strongest evidence-based link to learning processes and plasticity is depicted in Figure 7 (mean $+/$ - SEM).

\section{Discussion}

Physical training after photothrombotic stroke significantly and permanently improved functional recovery after stroke. Forced arm use was clearly superior to voluntary training in terms of sensorimotor recovery. Both the general effect of any physical training, as well as the difference between FAU and VE are reflected in gene expression profiles obtained from 3 different brain regions involved in recovery processes of the post-stroke brain. Gene expression changes differing between both training paradigms identify plasticity-relevant groups.

Recent studies clearly provided proof for forced arm use or constraint induced movement therapy to be effective training paradigms for improving motor function of the affected upper extremity after stroke [4-6]. A characteristic of this specific motor therapy compared to standard physical therapy is the intensiveness of the training and its high degree in standardization. Both together forces the patient to an increased active use of the paralyzed arm hereby improving gross and fine motor function. Interestingly, less intense training paradigms such as motor skill training are also suited to improve motor function of the affected extremity after a stroke compared to paradigms of less intensity such as voluntary running $[61,62]$. A gradually further deescalated training paradigm, where rodents control the daily intensity and the timing of the training by themselves, voluntary training, can potentially improve motor function after an insult but had in several other studies no effect (for review see [63]). Overall these findings suggest that a physical training is the more effective the more structured and intense it is.

Forced arm use or constraint induced movement therapy can principally be applied to all patients with a medium or medium-severe paresis of the arm independent of the localization of the infarction [6]. Experimental data suggest, however, that overuse in the hyperacute phase of a developing lesion might be detrimental, impair motor function, and attenuate lesion size [7-10]. These findings are corroborated by a recent clinical study, where constraint induced movement therapy applied in the early subacute phase after stroke (starting day 10 post-stroke) was not superior to standard physical therapy [64]. Moreover, an intensified constraint induced treatment arm in this study (extended treatment interval of 3 hours compared to 2 hours in the regular arm) produced an even worse outcome at the end of the observation period (90 days post-stroke). These findings illustrate that this type of treatment is highly effective but a careful selection of the timing and dosing is warranted, something that currently has just been partly explored. A biological explanation for this observation might be that induction of additional stress onto already compromised brain tissue in the periphery of a lesion may further compromise this brain tissue and finally impair recovery or exaggerate lesion size.

Forced arm use and other forced training paradigms lead to a number of processes in the brain, so called plasticity-related structural changes. Such changes include the induction of neurogenesis in the subgranular zone [65], regulation of growth factor receptors and release of their ligands such as BDNF or IGF-I [66], activation of proteins for synaptic and dendritic plasticity such as MAP-2, synapsin, or synaptophysin [19,67], and up regulation of AMPA receptors [18].

We confirm this strong influence of post-stroke training (both voluntary and FAU) on basal neuronal plasticity mechanisms, and find up regulation of NTRK2, NMDA 2a receptor, or MAP1b. Correlated to the behavioral observations, forced arm use generally leads to a stronger regulation of genes (both up - and down regulation) than voluntary training, reflecting the clinical observation that intensity and structure is a strong driver to improve motor function.

In conclusion, we have shown that intensive and structured training paradigms such as forced arm use result in the best functional motor outcome after stroke. This is reflected by a quantitative, but not qualitative, change in the gene expression program linked to recovery through training. These findings may open new approaches to further improve post-stroke rehabilitation and to develop adjunctive pharmacological therapies after stroke.

\section{Additional files}

Additional file 1: Figure S1. Shows the relative position of the horizontal sections used for dissection (A), and an exemplary view on the stained hippocampus before and after laser microdissection (B).

Additional file 2: Figure S2. Electropherogram of amplified RNA (Agilent Bioanalyzer). Note the excellent size distribution of the amplified RNA. Ladder size (Agilent RNA 6000): 0.2 kb, 0.5 kb, 1.9 kb, 2.9 kb, 4.0 kb, $6.0 \mathrm{~kb}$.

Additional file 3: Figure S3. Quality control for the distribution of signal intensities on the Affymetrix array. The distribution is highly homogenous over all groups with no outliers. 
Additional file 4: Figure S4. Overview of all two-way comparisons as scatter plots, red: up regulated genes, green: down regulated genes (Welch's t-test, false discovery rate correction: Benjamini Hochberg, threshold: 1.5). "cast" = forced arm use, "volu" = voluntary exercise, "cage controls" = control animals. It is obvious that far fewer genes are changed between the two training paradigms than between each training paradigm and the control animals.

Additional file 5: Table S1. Given are 3613 probe sets that were significantly influenced by the factor exercise (significance criteria: $p<0.01$ after multiple testing adjustment for Benjamini-Hochberg false discovery rate). Numbers in the column titles signify different exercise paradigms in the 3 different locations: $1-3$, cortex ipsilateral $(1=$ control, 2 = voluntary, 3 = forced training); $4-6$, hippocampus ( $4=$ control, $5=$ voluntary, $6=$ forced training); $7-9$, cortex contralateral $(7=$ control, $8=$ voluntary, $9=$ forced training). "Mean" are the log2 transformed values, with "SEM" being the standard error of the mean for each group. "Mean norm" are the non-transformed intensity values for each group. "gene identifier", "gene title" etc. give information for the identities of the probe set.

\section{Competing interests}

The authors declare no competing interest linked to this study.

\section{Authors' contributions}

AS and WRS designed the study, and drafted the manuscript. AR, JM and KD performed animal experiments, OW and GV performed statistical array analyses, NG performed array hybridizations, FK, CK, ChP performed histological work, laser microdissection, RNA preparation and amplification, $\mathrm{CP}$ and $\mathrm{RL}$ were involved in data evaluation and discussions. All authors read and approved the final manuscript.

\section{Acknowledgements}

We thank Gisela Eisenhardt, Nadine Schramm, Vera Sonntag-Buck, and Ulrike Bolz for expert technical assistance. This work was funded by the German National Genome Research Network-2 (NGFN-2).

\section{Author details}

${ }^{1}$ SYGNIS Bioscience, Heidelberg, Germany. ${ }^{2}$ Neurology Department Bethel EVKB Bielefeld and Dept. of Neurology, University of Muenster, Muenster, Germany. ${ }^{3} \mathrm{Ctr}$. for Med. Res., Fac. for Clin. Medicine, University of Heidelberg, Mannheim, Germany.

Received: 7 January 2014 Accepted: 26 January 2014 Published: 14 February 2014

\section{References}

1. Lloyd-Jones D, Adams RJ, Brown TM, Carnethon M, Dai S, De Simone G, Ferguson TB, Ford E, Furie K, Gillespie C, et al: Heart disease and stroke statistics-2010 update: a report from the American Heart Association. Circulation 2010, 121(7):e46-e215.

2. Cramer SC: Repairing the human brain after stroke II. Restorative therapies. Ann Neurol 2008, 63(5):549-560.

3. Miltner WH, Bauder H, Sommer M, Dettmers C, Taub E: Effects of constraint-induced movement therapy on patients with chronic motor deficits after stroke: a replication. Stroke 1999, 30(3):586-592.

4. Wolf SL, Winstein CJ, Miller JP, Taub E, Uswatte G, Morris D, Giuliani C, Light KE, Nichols-Larsen D: Effect of constraint-induced movement therapy on upper extremity function 3 to 9 months after stroke: the EXCITE randomized clinical trial. JAMA 2006, 296(17):2095-2104.

5. Taub E, Uswatte G, King DK, Morris D, Crago JE, Chatterjee A: A placebocontrolled trial of constraint-induced movement therapy for upper extremity after stroke. Stroke 2006, 37(4):1045-1049.

6. Gauthier LV, Taub E, Mark WW, Perkins C, Uswatte G: Improvement after constraint-induced movement therapy is independent of infarct location in chronic stroke patients. Stroke 2009, 40(7):2468-2472.

7. Kozlowski DA, James DC, Schallert T: Use-dependent exaggeration of neuronal injury after unilateral sensorimotor cortex lesions. J Neurosci 1996, 16(15):4776-4786.
8. Risedal A, Zeng J, Johansson BB: Early training may exacerbate brain damage after focal brain ischemia in the rat. $J$ Cereb Blood Flow Metab 1999, 19(9):997-1003.

9. Leasure $\mathrm{J}$, Schallert $\mathrm{T}$ : Consequences of forced disuse of the impaired forelimb after unilateral cortical injury. Behav Brain Res 2004, 150(1-2):83-91.

10. Humm JL, Kozlowski DA, James DC, Gotts JE, Schallert T: Use-dependent exacerbation of brain damage occurs during an early post-lesion vulnerable period. Brain Res 1998, 783(2):286-292.

11. Nudo RJ, Wise BM, SiFuentes F, Milliken GW: Neural substrates for the effects of rehabilitative training on motor recovery after ischemic infarct. Science 1996, 272(5269):1791-1794.

12. Butefisch CM, Kleiser R, Korber B, Muller K, Wittsack HJ, Homberg V, Seitz RJ: Recruitment of contralesional motor cortex in stroke patients with recovery of hand function. Neurology 2005, 64(6):1067-1069.

13. Ronnback A, Dahlqvist P, Svensson PA, Jernas M, Carlsson B, Carlsson LM, Olsson T: Gene expression profiling of the rat hippocampus one month after focal cerebral ischemia followed by enriched environment. Neurosci Lett 2005, 385(2):173-178.

14. Dietrich WD, Ginsberg MD, Busto R, Watson BD: Photochemically induced cortical infarction in the rat. 2 . Acute and subacute alterations in local glucose utilization. J Cereb Blood Flow Metab 1986, 6(2):195-202.

15. Dietrich WD, Ginsberg MD, Busto R, Watson BD: Photochemically induced cortical infarction in the rat. 1. Time course of hemodynamic consequences. J Cereb Blood Flow Metab 1986, 6(2):184-194.

16. Newrzella D, Pahlavan PS, Kruger C, Boehm C, Sorgenfrei O, Schrock H, Eisenhardt G, Bischoff N, Vogt G, Wafzig O, et al: The functional genome of CA1 and CA3 neurons under native conditions and in response to ischemia. BMC Genomics 2007, 8:370.

17. Rossner MJ, Hirrlinger J, Wichert SP, Boehm C, Newrzella D, Hiemisch H, Eisenhardt G, Stuenkel C, von Ahsen O, Nave KA: Global transcriptome analysis of genetically identified neurons in the adult cortex. J Neurosci 2006, 26(39):9956-9966.

18. Muller HD, Hanumanthiah KM, Diederich K, Schwab S, Schabitz WR, Sommer C: Brain-derived neurotrophic factor but not forced arm use improves long-term outcome after photothrombotic stroke and transiently upregulates binding densities of excitatory glutamate receptors in the rat brain. Stroke 2008, 39(3):1012-1021.

19. Schabitz WR, Berger C, Kollmar R, Seitz M, Tanay E, Kiessling M, Schwab S, Sommer C: Effect of brain-derived neurotrophic factor treatment and forced arm use on functional motor recovery after small cortical ischemia. Stroke 2004, 35(4):992-997.

20. Thalamuthu A, Mukhopadhyay I, Zheng X, Tseng GC: Evaluation and comparison of gene clustering methods in microarray analysis. Bioinformatics 2006, 22(19):2405-2412.

21. da Huang W, Sherman BT, Lempicki RA: Systematic and integrative analysis of large gene lists using DAVID bioinformatics resources. Nat Protoc 2009, 4(1):44-57.

22. Huang Da W, Sherman BT, Tan Q, Kir J, Liu D, Bryant D, Guo Y, Stephens R, Baseler MW, Lane HC, et al: DAVID Bioinformatics Resources: expanded annotation database and novel algorithms to better extract biology from large gene lists. Nucleic Acids Res 2007, 35:W169-W175.

23. Bannerman DM, Bus T, Taylor A, Sanderson DJ, Schwarz I, Jensen V, Hvalby O, Rawlins JN, Seeburg PH, Sprengel R: Dissecting spatial knowledge from spatial choice by hippocampal NMDA receptor deletion. Nat Neurosci 2012, 15(8):1153-1159.

24. Bannerman DM, Niewoehner B, Lyon L, Romberg C, Schmitt WB, Taylor A, Sanderson DJ, Cottam J, Sprengel R, Seeburg PH, et al: NMDA receptor subunit NR2A is required for rapidly acquired spatial working memory but not incremental spatial reference memory. J Neurosci 2008, 28(14):3623-3630.

25. Berberich S, Jensen V, Hvalby O, Seeburg PH, Kohr G: The role of NMDAR subtypes and charge transfer during hippocampal LTP induction. Neuropharmacology 2007, 52(1):77-86.

26. Burnashev N, Schoepfer R, Monyer H, Ruppersberg JP, Gunther W, Seeburg $\mathrm{PH}$, Sakmann B: Control by asparagine residues of calcium permeability and magnesium blockade in the NMDA receptor. Science 1992, 257(5075):1415-1419.

27. Monyer H, Sprengel R, Schoepfer R, Herb A, Higuchi M, Lomeli H, Burnashev N, Sakmann B, Seeburg PH: Heteromeric NMDA receptors: molecular and functional distinction of subtypes. Science 1992, 256(5060):1217-1221. 
28. Black IB: Trophic regulation of synaptic plasticity. J Neurobio/ 1999, 41(1):108-118.

29. Ebendal T: Function and evolution in the NGF family and its receptors. J Neurosci Res 1992, 32(4):461-470.

30. Lu B, Nagappan G, Guan X, Nathan PJ, Wren P: BDNF-based synaptic repair as a disease-modifying strategy for neurodegenerative diseases. Nat Rev Neurosci 2013, 14(6):401-416.

31. Schabitz WR, Steigleder T, Cooper-Kuhn CM, Schwab S, Sommer C, Schneider A, Kuhn HG: Intravenous brain-derived neurotrophic factor enhances poststroke sensorimotor recovery and stimulates neurogenesis. Stroke 2007, 38(7):2165-2172.

32. Middlemas DS, Lindberg RA, Hunter T: trkB, a neural receptor proteintyrosine kinase: evidence for a full-length and two truncated receptors. Mol Cell Biol 1991, 11(1):143-153.

33. Bettler B, Boulter J, Hermans-Borgmeyer I, O'Shea-Greenfield A, Deneris ES, Moll C, Borgmeyer U, Hollmann M, Heinemann S: Cloning of a novel glutamate receptor subunit, GluR5: expression in the nervous system during development. Neuron 1990, 5(5):583-595.

34. Herb A, Higuchi M, Sprengel R, Seeburg PH: Q/R site editing in kainate receptor GluR5 and GluR6 pre-mRNAs requires distant intronic sequences. Proc Natl Acad Sci U S A 1996, 93(5):1875-1880.

35. Bortolotto ZA, Clarke VR, Delany CM, Parry MC, Smolders I, Vignes M, Ho KH, Miu P, Brinton BT, Fantaske $R$, et al: Kainate receptors are involved in synaptic plasticity. Nature 1999, 402(6759):297-301.

36. Jane DE, Lodge D, Collingridge GL: Kainate receptors: pharmacology, function and therapeutic potential. Neuropharmacology 2009, 56(1):90-113.

37. Ko S, Zhao MG, Toyoda H, Qiu CS, Zhuo M: Altered behavioral responses to noxious stimuli and fear in glutamate receptor 5 (GluR5)- or GluR6-deficient mice. J Neurosci 2005, 25(4):977-984.

38. Oren I, Nissen W, Kullmann DM, Somogyi P, Lamsa KP: Role of ionotropic glutamate receptors in long-term potentiation in rat hippocampal CA1 oriens-lacunosum moleculare interneurons. J Neurosci 2009, 29(4):939-950.

39. Dickinson BA, Jo J, Seok H, Son GH, Whitcomb DJ, Davies CH, Sheng M, Collingridge GL, Cho K: A novel mechanism of hippocampal LTD involving muscarinic receptor-triggered interactions between AMPARs GRIP and liprin-alpha. Molecular brain 2009, 2:18.

40. Dong H, O'Brien RJ, Fung ET, Lanahan AA, Worley PF, Huganir RL: GRIP: a synaptic PDZ domain-containing protein that interacts with AMPA receptors. Nature 1997, 386(6622):279-284.

41. Liu SJ, Cull-Candy SG: Subunit interaction with PICK and GRIP controls Ca2+ permeability of AMPARs at cerebellar synapses. Nat Neurosci 2005, 8(6):768-775.

42. Mao L, Takamiya K, Thomas G, Lin DT, Huganir RL: GRIP1 and 2 regulate activity-dependent AMPA receptor recycling via exocyst complex interactions. Proc Natl Acad Sci U S A 2010, 107(44):19038-19043.

43. Jaubert PJ, Golub MS, Lo YY, Germann SL, Dehoff MH, Worley PF, Kang SH, Schwarz MK, Seeburg PH, Berman RF: Complex, multimodal behavioral profile of the Homer1 knockout mouse. Genes Brain Behav 2007, 6(2):141-154.

44. Szumlinski KK, Dehoff MH, Kang SH, Frys KA, Lominac KD, Klugmann M, Rohrer J, Griffin W 3rd, Toda S, Champtiaux NP, et al: Homer proteins regulate sensitivity to cocaine. Neuron 2004, 43(3):401-413.

45. Wagner KV, Hartmann J, Mangold K, Wang XD, Labermaier C, Liebl C, Wolf M, Gassen NC, Holsboer F, Rein T, et al: Homer1 mediates acute stressinduced cognitive deficits in the dorsal hippocampus. J Neurosci 2013, 33(9):3857-3864

46. Brakeman PR, Lanahan AA, O'Brien R, Roche K, Barnes CA, Huganir RL, Worley PF: Homer: a protein that selectively binds metabotropic glutamate receptors. Nature 1997, 386(6622):284-288.

47. Kammermeier PJ, Xiao B, Tu JC, Worley PF, Ikeda SR: Homer proteins regulate coupling of group I metabotropic glutamate receptors to N-type calcium and M-type potassium channels. J Neurosci 2000, 20(19):7238-7245.

48. Sacktor TC: PKMzeta, LTP maintenance, and the dynamic molecular biology of memory storage. Prog Brain Res 2008, 169:27-40.

49. Sacktor TC, Osten P, Valsamis H, Jiang X, Naik MU, Sublette E: Persistent activation of the zeta isoform of protein kinase $C$ in the maintenance of long-term potentiation. Proc Natl Acad Sci U S A 1993, 90(18):8342-8346.
50. Serrano P, Friedman EL, Kenney J, Taubenfeld SM, Zimmerman JM, Hanna J, Alberini C, Kelley AE, Maren S, Rudy JW, et al: PKMzeta maintains spatial, instrumental, and classically conditioned long-term memories. PLoS biology 2008, 6(12):2698-2706.

51. Yao Y, Shao C, Jothianandan D, Tcherepanov A, Shouval H, Sacktor TC: Matching biochemical and functional efficacies confirm ZIP as a potent competitive inhibitor of PKMzeta in neurons. Neuropharmacology 2013, 64:37-44.

52. Lee AM, Kanter BR, Wang D, Lim JP, Zou ME, Qiu C, McMahon T, Dadgar J, Fischbach-Weiss SC, Messing RO: Prkcz null mice show normal learning and memory. Nature 2013, 493(7432):416-419.

53. Kremerskothen J, Plaas C, Buther K, Finger I, Veltel S, Matanis T, Liedtke T, Barnekow A: Characterization of KIBRA, a novel WW domain-containing protein. Biochem Biophys Res Commun 2003, 300(4):862-867.

54. Muse J, Emery M, Sambataro F, Lemaitre H, Tan HY, Chen Q, Kolachana BS, Das S, Callicott JH, Weinberger DR, et al: WWC1 Genotype modulates Agerelated decline in episodic memory function across the adult life span. Biol Psych 2013, S0006-3223(13):00945-1.

55. Papassotiropoulos A, Stephan DA, Huentelman MJ, Hoerndli FJ, Craig DW, Pearson JV, Huynh KD, Brunner F, Corneveaux J, Osborne D, et al: Common Kibra alleles are associated with human memory performance. Science 2006, 314(5798):475-478

56. Schneider A, Huentelman MJ, Kremerskothen J, Duning K, Spoelgen R, Nikolich K: KIBRA: a New gateway to learning and memory? Front Aging Neurosci 2010, 2:4

57. Vogt-Eisele A, Kruger C, Duning K, Weber D, Spoelgen R, Pitzer C, Plaas C, Eisenhardt G, Meyer A, Vogt G, et al: KIBRA (KIdney/BRAin protein) regulates learning and memory and stabilizes Protein kinase Mzeta. J Neurochem 2013. doi:10.111/jnc.12480.

58. Wang DC, Liu PC, Hung HS, Chen TJ: Both PKMzeta and KIBRA are closely related to reference memory but not working memory in a T-maze task in rats. J Comp Physiol A Neuroethol Sens Neural Behav Physiol 2014, 200(1):77-82.

59. Kauppi K, Nilsson LG, Adolfsson R, Eriksson E, Nyberg L: KIBRA polymorphism is related to enhanced memory and elevated hippocampal processing. J Neurosci 2011, 31(40):14218-14222.

60. Makuch L, Volk L, Anggono V, Johnson RC, Yu Y, Duning K, Kremerskothen J, Xia J, Takamiya K, Huganir RL: Regulation of AMPA receptor function by the human memory-associated gene KIBRA. Neuron 2011, 71(6):1022-1029.

61. Maldonado MA, Allred RP, Felthauser EL, Jones TA: Motor skill training, but not voluntary exercise, improves skilled reaching after unilateral ischemic lesions of the sensorimotor cortex in rats. Neurorehabil Neural Repair 2008, 22(3):250-261.

62. Komitova M, Zhao LR, Gido G, Johansson BB, Eriksson P: Postischemic exercise attenuates whereas enriched environment has certain enhancing effects on lesion-induced subventricular zone activation in the adult rat. Eur J Neurosci 2005, 21(9):2397-2405.

63. Vaynman S, Gomez-Pinilla F: License to run: exercise impacts functional plasticity in the intact and injured central nervous system by using neurotrophins. Neurorehabil Neural Repair 2005, 19(4):283-295.

64. Dromerick AW, Lang CE, Birkenmeier RL, Wagner JM, Miller JP, Videen TO, Powers WJ, Wolf SL, Edwards DF: Very early constraint-induced movement during stroke rehabilitation (VECTORS): a single-center RCT. Neurology 2009, 73(3):195-201.

65. Lee SH, Kim YH, Kim YJ, Yoon BW: Enforced physical training promotes neurogenesis in the subgranular zone after focal cerebral ischemia. J Neurol Sci 2008, 269(1-2):54-61.

66. Ploughman M, Granter-Button S, Chernenko G, Attwood Z, Tucker BA, Mearow KM, Corbett D: Exercise intensity influences the temporal profile of growth factors involved in neuronal plasticity following focal ischemia. Brain Res 2007, 1150:207-216.

67. Ploughman M, Attwood Z, White N, Dore JJ, Corbett D: Endurance exercise facilitates relearning of forelimb motor skill after focal ischemia. Eur $J$ Neurosci 2007, 25(11):3453-3460.

doi:10.1186/2040-7378-6-3

Cite this article as: Schneider et al:: Forced arm use is superior to voluntary training for motor recovery and brain plasticity after cortical ischemia in rats. Experimental \& Translational Stroke Medicine 2014 6:3. 